Owais M., et al., Optimal circular bus routes planning for transit network design problem in urban areas, pp. $1447-1466$

\title{
OPTIMAL CIRCULAR BUS ROUTES PLANNING FOR TRANSIT NETWORK DESIGN PROBLEM IN URBAN AREAS
}

\author{
Owais M. M. ", Salah G., Abbas Y A., El-Shabrawy, M. M. \\ Civil Engineering Department, Faculty of Engineering, Assiut University, Assiut, Egypt
}

Received 27 April 2013, accepted 4 July 2013

\begin{abstract}
This paper presents a deterministic solution methodology for Transit route Network Design Problem (TrNDP). The main objective is to design a set of bus routes minimizing both users and operator costs while satisfying some constraints; such as minimum demand trips coverage, maximum bus route length and route directness. The proposed methodology provides an efficient set of circular closed bus routes. The formulation of the methodology consists of three parts; 1 - representation of transit route network and input data, 2- representation of transit route network objectives and constraints as mathematical programming, 3- the structure of the solution methodology for bus route design. The methodology structure has been tested through Mandl's benchmark network problem. The test results showed that the methodology developed in this study is able to improve a given network solution in terms of number of constructed routes, transit service coverage, transfer directness, and solution reliability. Based on the presented methodology, a more robust network optimization tool would be produced for public transportation planning purposes.
\end{abstract}

Keyword: Optimal transit network, Route design problem, Constructive algorithms.

\section{Introduction}

Public transportation planning is a very important means to reduce traffic congestions, improve urban environmental conditions and consequently affect people social lives [1]. A key component in public transportation planning is the Transit Network Design problem (TNDP). The TNDP aims to design a set of bus routes and manage these routes operation in an efficient manner for both users and operators. Different system functions and targets, required for each group of participants, have to be met through solution methodology. TNDP, stated simply, relates to the determination of a set of routes defined over the street network with their corresponding schedules to deal with demand trips [2].

Transit route network design is the most important component in TNDP, where the overall cost of the public transportation system highly depends on it. Once the transit network is defined, a set of routes is identified over the street network and subsequently all decisions about timetable development, bus and driver scheduling are conditioned to it [3].

An efficient route between two nodes is the shortest one between them while fulfilling users and operator goals. Designing efficient bus route, which combines maximum demand potential coverage and time constraint for maximum bus route length, should use algorithms that operate in the same way as those of finding shortest path [1]. Set of bus routes should have the following properties [2]:

1. The route set should satisfy most, if not all the existing transit demand.

Corresponding author.

E-mail address: maowais@yahoo.com 
Owais M., et al., Optimal circular bus routes planning for transit network design problem in urban areas, pp. 1447 - 1466

2. Most of the (O/D) trips would be accomplished without transfer from one route to another, if possible.

3. The route set should offer least cost for both users and operators.

Transit route design is a sophisticated problem, since route design is directly associated with bus frequency which is included in TNDP as a decision variable, also given the discrete nature of some of its variables (routes) and continuous variables (operation variables). Main problem data are the street network structure and the demand trips between different traffic zones of the city. Problem constraints refer usually to demand coverage and resources availability [3, 4, and 5]. For these reasons, most existing approaches to solve TNDP rely on approximate methods such as; heuristics and Meta heuristics procedures.

TNDP has been tackled in many researches, each research considered different objective function, problem Mathematical Programming representation and search algorithm (heuristics or Meta - heuristic) to be implemented in the solution. Some works exist in the literature about heuristics and Meta heuristics algorithms to construct a set of routes for the TNDP, while ensuring demand coverage feasibility [1, 6, and 7].

Pattnnik et al., 1998, implemented a two phase's procedure for TNDP. First phase, a set of feasible bus routes would be generated through heuristic procedure and second phase Genetic Algorithm (GA) was applied to select optimal (or near - optimal) bus routes network. Their objective was to minimize the total system cost for users and operator [7].

Gao et al., 2004, proposed a bi - level programming model for TNDP which incorporated upper level objective function (Bus network design model) and lower objective function (transit equilibrium assignment model). Their solution approach focused on the interaction between supply side and demand side similar to continuous equilibrium network design problem. Solution algorithm based on sensitivity analysis was used for the proposed model [8].

Guan et al., 2006, developed TNDP solution as integer Mathematical Programming taking into account transit route configuration and transit passenger's assignment simultaneously. Their model consisted of three weighted terms representing total route cost, total passenger in - vehicle time and total number of transfers. Their objective function balanced between transit route operator cost and passengers cost through the value of weighted factors. They indicated that it could be easily solved by standard branch and bound algorithm, since all model's variables were integer [9].

$\mathrm{Yu}$ and Yang, 2012, assigned trips incrementally to transit network to reach an approximate equilibrium. Each portion was assigned to shortest path between origin and destination. After each assignment, the network travel time was updated by shortest hyper path algorithm calculating expecting waiting time and the change in the shortest hyper path. Ant Colony Optimization was used to generate three types of bus routes to cover transit network demand, namely; skeleton, main and branch routes [10].

From reviewing pervious literature works regarding Transit Network Design Problem (TNDP), there are some remarkable notes which would be sated as follows:

1. Heuristic approaches are always able to provide feasible solutions but they don't guarantee the global optimal solution.

Journal of Engineering Sciences, Assiut University, Faculty of Engineering, Vol. 41, No. 4, July, 2013,E-mail address: jes@aun.edu.eg 
Owais M., et al., Optimal circular bus routes planning for transit network design problem in urban areas, pp. 1447 - 1466

2. Meta - Heuristic approaches search space for route construction algorithm are usually take tremendously computational effort and much more CPU time than deterministic approaches would take.

3. The success of the Meta - Heuristic approaches depends heavily on the quality of the chosen representation and the effectiveness of the initialization procedures. The implementation of the shortest routes between demand centers in pervious literature is not always efficient as far as demand coverage is concerned.

Therefore, in order to overcome pervious mentioned and short comings reviewed so - far in pervious woks, it is essential to provide a consistent mathematical formulation algorithm of the problem and its solution to reach best value of route directness, maximum service coverage, minimum transfers and minimum users and operators transport costs.

Aimed objectives of this research part is to reach a simple and efficient methodology for optimal transit route design which gives procedure for solving TNDP and would be rather most applicable for small, medium and large size networks, and also conform to several network routes configurations. The aimed methodology goes away from sophisticated techniques reviewed so far in the literature. This approach also would overcome solution difficulty for TNDP due to non - convex nature of the problem and the combinatorial intractability between users and operators goals (multi - objective) optimization [11].

Solution methodology adopted in this research for TNDP is based on an approach to partition the complexity of solving these two stages simultaneously into two consecutive stages;

First stage: Physical route design (optimal transit route generation to serve passengers demand while minimizing transit network routes length).

Second stage: Transit route service management fulfilling users and operator goals (optimal vehicle fleet size and scheduling to serve passengers demand).

This paper proposes a solution algorithm for handling bus routes design (efficient routes). The results of the first component (parameters) are applied as input for 2nd stage which isn't included in this paper.

\section{Transit route generation problem}

\section{1. Problem definition}

Passengers transport is caused by passengers' demands for travel among Origin Destination (O/D) locations. Each zone has associated with one zone centroid and group of passengers with their associated (O/D) trips desires which are concentrated at zone centroid. Transit modes supply services are routed in an environment to pick - up and deliver passengers demand among - what is called - Transit (O/D) locations through selection of efficient bus routes from a given network routes configurations. The problem is to select efficient set of bus routes through deterministic methodology (network models) guided by criterion to reach maximum demand potential coverage and time constraint for maximum bus route length [11].

Journal of Engineering Sciences, Assiut University, Faculty of Engineering, Vol. 41, No. 4, July, 2013,E-mail address: jes@aun.edu.eg 
Owais M., et al., Optimal circular bus routes planning for transit network design problem in urban areas, pp. $1447-1466$

\section{2. Solution methodology objectives and constrains}

Solution methodology objectives aim to achieve some goals under satisfying some constraints. Transit network users and operators are the main concern to transit routing design problem. The main objective is to design set of routes minimizing both users and operator costs and satisfy some constraints, such as; route directness, route maximum length, minimum demand coverage directly and maximum demand covered indirectly.

Route directness $(\mathrm{d}(\mathrm{R}))$ is an indicator to measure bus route deviation from the shortest path among main transit nodes pairs since; $\mathrm{d}(\mathrm{R})=1$ indicates that all bus users would take the shortest path along their travel between origin and destination. Value of $d(R)$ which exceeds one, it would indicate the delay caused by the set of bus routes to all users.

Mathematical models and notations representing objectives and constraints of Bus Route Design:

a- Objectives:

1- For all users minimize $\mathrm{Z}_{\mathrm{u}}(\mathrm{R})=\sum_{\mathrm{i} e N} \sum_{j \in N} \mathrm{~d}_{\mathrm{i}-\mathrm{j}} \times t_{i-j}^{r}$

2- For operator minimize $\mathrm{Z}_{\mathrm{o}}(\mathrm{R})=\sum_{\mathrm{r} \in R} \mathrm{~T}^{\mathrm{r}}$

b- Constraints:

1- Demand coverage:

$$
\begin{aligned}
& D_{0}(R) \geq D_{o}{ }^{{ }^{m i n}} \\
& D_{01}(R) \leq D_{o 1}{ }^{{ }^{m a x}} \\
& D_{\text {tot }}(R)=D_{0}+D_{01} \geq D_{\text {tot }}{ }^{\text {min }}
\end{aligned}
$$

2- Bus routes network directness indicator:

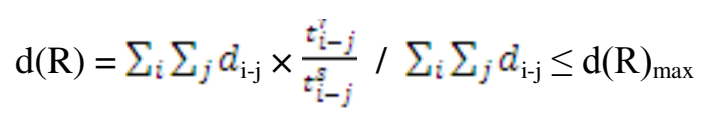

3- Maximum bus route length (travel time):

$$
\mathrm{T}^{\mathrm{r}}=\sum_{\tilde{i}}^{m-1} \sum_{j=i+1}^{m} t_{i-j}^{r} \leq \mathrm{T}^{\mathrm{r}}{ }_{\max }
$$

Journal of Engineering Sciences, Assiut University, Faculty of Engineering, Vol. 41, No. 4, July, 2013, E-mail address: jes@aun.edu.eg 
Owais M., et al., Optimal circular bus routes planning for transit network design problem in urban areas, pp. 1447 - 1466

Where;

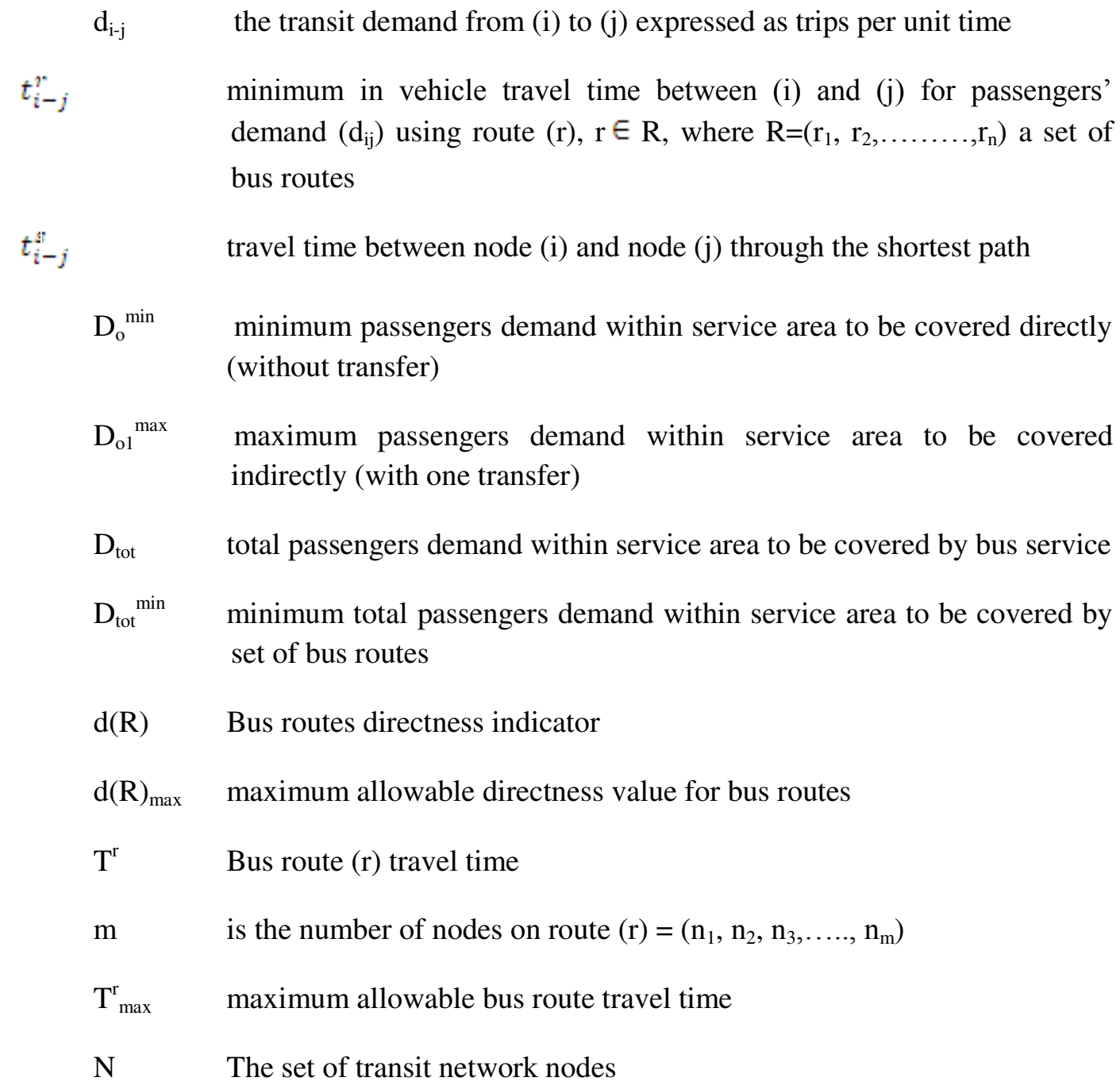

\subsection{Solution methodology approach}

It is obvious from the literature that Route design process is difficult to be solved deterministically to reach global optimal solution. There have been many worthwhile researches on transit network route design through heuristics approach. Good (near optimal solution) is the target for most of these researches. Representing Route design Algorithm as Mathematical Programming (MP) has taken many forms depending on the variables considered in solution and objective function. Generally, searching for more realistic Mathematical programming representation would result in formulations which are difficult to be solved with traditional techniques [2].

Journal of Engineering Sciences, Assiut University, Faculty of Engineering, Vol. 41, No. 4, July, 2013,E-mail address: jes@aun.edu.eg 
Owais M., et al., Optimal circular bus routes planning for transit network design problem in urban areas, pp. $1447-1466$

Solution methodology approach in this research is based on three steps. These steps include consecutive procedures which have been adopted to alleviate the complexity of Transit Route design problem.

First step, All or-Nothing assignment technique is implemented to assign main transit nodes trips to network. This step depends on the shortest route between selected nodes, and thus it asserts that all transit users would take the shortest path to their destination (minimization user cost). The assigned loaded network is considered as base - Transit network to the rest of the solution methodology.

Second step, Linear Programming (LP) algorithm to optimize the network by maximizing the flow on the network by considering two constraints;

1- Maximum trips on any link shouldn't exceed the value obtained from (first step).

2- Nodes conservation equilibrium shouldn't be violated. The second constraint asserts that the number of trips terminated at node is equal to the number of trips started at the same node and thus creating assigned equilibrated network flows on links. This step would cause every bus on the transit network to run with the same load factor along its route which will give high efficiency to bus system (least cost).

Third step, Route Construction Algorithm through Integer Programming (IP) which is proposed to create a set of circular closed bus routes to achieve maximum direct demand coverage (-0- transfer) without violating bus route length constraint for selected main transit nodes. Each bus route would be assigned with a defined lower bound demand load which is used in the scheduling of service.

\subsection{Network representation}

The term "network" in transportation planning is used to describe a structure of streets and intersections to be used in Mathematical Programming (MP). MP models have practical applications in solving traffic problems. Moreover, a network is a graph in which arcs have an associated flow. A graph is a structure that is built by interconnecting nodes and arcs; figure (1.a). A directed graph is a graph in which the arcs have specified directions by arrow heads as shown in figure (1.b). The graph representation of the urban network can vary from planner to another depending on the level of required detail, available data and analysis technique. Given an urban network that enables the definition of routes as a graph $G=(N, A)$, where $(N)$ is the set of nodes $(|\mathrm{N}|=\mathrm{n})$. The set of nodes are connected by the set of $\operatorname{arcs}(\operatorname{links})(|\mathrm{A}|=\mathrm{a}) .[12]$.

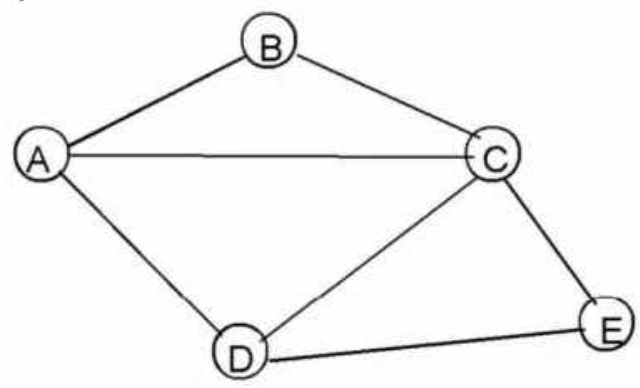

a- Graph

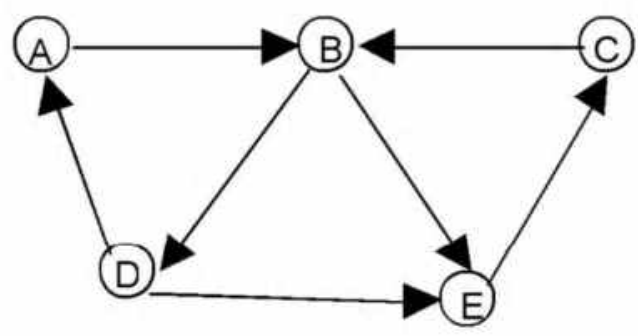

b- Directed graph

Fig. 1. Graphs and directed graphs [12]

Journal of Engineering Sciences, Assiut University, Faculty of Engineering, Vol. 41, No. 4, July, 2013,E-mail address: jes@aun.edu.eg 
Owais M., et al., Optimal circular bus routes planning for transit network design problem in urban areas, pp. 1447 - 1466

\section{Overview of deterministic route generation algorithm (DRGA)}

This research develops a Deterministic Route Generation Algorithm (DGRA) which is a design solution for constructing efficient bus routes in an urban road network. It aims to maximize transit network capability of transporting passengers through designing optimal bus routes satisfying the needs for both users and operators. This can be attained by maximizing the number of trips transported through shortest path routes, while maximizing the demand coverage of trips. These objectives would be achieved through implemented constructive algorithms. These algorithms work in sequential order in which each algorithm output gives input to the next algorithm.

\section{1. Required input data}

DRGA is a deterministic design algorithm that is heavily guided by the demand trips $(O / D$ matrix). DRGA input data may be grouped under four categories, summarized in table (1).

\section{Table 1}

Input Data

\begin{tabular}{cl}
\hline Input category & \multicolumn{1}{c}{ Category item } \\
\hline \multirow{2}{*}{ Network } & -Coded network with travel time on links. \\
& -Number of Main Transit nodes $(N)$. \\
\hline \multirow{2}{*}{ Demand } & -Transit Demand matrix $($ O/D matrix). \\
& -Minimum percentage of total demand satisfied directly. \\
& -Maximum percentage of total demand satisfied indirectly \\
\hline \multirow{2}{*}{ Parameters } & -Maximum Bus route time length. \\
& -Allowable routes directness \\
\hline
\end{tabular}

\subsection{DRGA initialization}

Although DRGA is capable of solving the entire network at once, reducing search space is an important factor in solving DRGA to make it more appropriate. Because of its deterministic manner, one would define initially the demand percentage to be served directly by required set of bus routes. To determine set of main transit nodes $(\mathrm{N})$, sort the transit demand matrix in decreasing order according to nodes total demand, and then choose the highest demand nodes (main transit nodes) which their total demand equal to or greater than Domin (minimum percentage of total demand satisfied directly).

\subsection{Implemented constructive algorithms}

Solution methodology is based on an approach that enables reaching aimed objectives, through implemented algorithms embedded in the solution procedure. These algorithms are:

1- Shortest path algorithm; builds the shortest path among all main transit nodes resulting in transit basic network.

Journal of Engineering Sciences, Assiut University, Faculty of Engineering, Vol. 41, No. 4, July, 2013,E-mail address: jes@aun.edu.eg 
Owais M., et al., Optimal circular bus routes planning for transit network design problem in urban areas, pp. 1447 - 1466

2- All - or - Nothing assignment algorithm; assigns every pair node transit trips on the shortest path between them. This would minimize the in - vehicle trip time for all users.

3- Linear programming algorithm; aims to maximize flow on the network by considering two constraints;

a- Maximum trips on any link shouldn't exceed the value obtained from assigned step.

b- Nodes conservation equilibrium shouldn't be violated. The second constraint asserts that the number of trips terminated at node is equal to the number of trips started at the same node and thus, every bus on the transit network would be running with the same load factor along its route which will give high efficiency to bus system (least cost) and ease the scheduling of bus service.

4- Integer programming algorithm; creates set of circular closed bus routes which cover the total demand for the selected main transit nodes directly and confirms with maximum route length.

These algorithms work in sequential order in which each algorithm output gives an input to the next algorithm. Main features of implemented algorithms are summarized in table (2).

\section{Table 2}

Implemented algorithms embedded in the solution methodology

\begin{tabular}{|c|c|c|}
\hline Algorithm & Function & objective \\
\hline Shortest route path algorithm & $\begin{array}{l}\text { Shortest route between }(\mathrm{i}, \mathrm{j}) \\
\text { nodes (minimum cost path) }\end{array}$ & \multirow{2}{*}{$\begin{array}{l}\text { Minimize in-vehicle travel } \\
\text { time for all users }\end{array}$} \\
\hline All - or - Nothing assignment & $\begin{array}{l}(\mathrm{O} / \mathrm{D}) \text { trips are loaded onto a } \\
\text { single, minimum cost path }\end{array}$ & \\
\hline Linear programming algorithm & $\begin{array}{l}\text { - Optimization of network flow } \\
\text { trips. } \\
\text { - Assign equilibrated flows on } \\
\text { network links } \\
\text { - Indentify the best set } \\
\text { combination of links' direction } \\
\text { to work together }\end{array}$ & Minimizing operator cost \\
\hline Integer programming algorithm & $\begin{array}{l}\text { - Identify a circular closed bus } \\
\text { route connecting high demand } \\
\text { loaded links. } \\
\text { - Bus route length confirms to } \\
\text { route length constraint. }\end{array}$ & $\begin{array}{l}\text { Maximizing demand } \\
\text { covered by bus routes }\end{array}$ \\
\hline
\end{tabular}

\section{Functions \& mathematical formulations of DRGA implemented algorithms}

\subsection{Shortest path algorithm}

Input: Given coded graph (network) with cost (distance or travel times) on links.

Function: A shortest path between pairs of main transit nodes (i,j) in coded graph.

Formulation: one of the most popular methods in this respect is Dijkstra's algorithm, figure (2).

Journal of Engineering Sciences, Assiut University, Faculty of Engineering, Vol. 41, No. 4, July, 2013, E-mail address: jes@aun.edu.eg 
Owais M., et al., Optimal circular bus routes planning for transit network design problem in urban areas, pp. 1447 - 1466

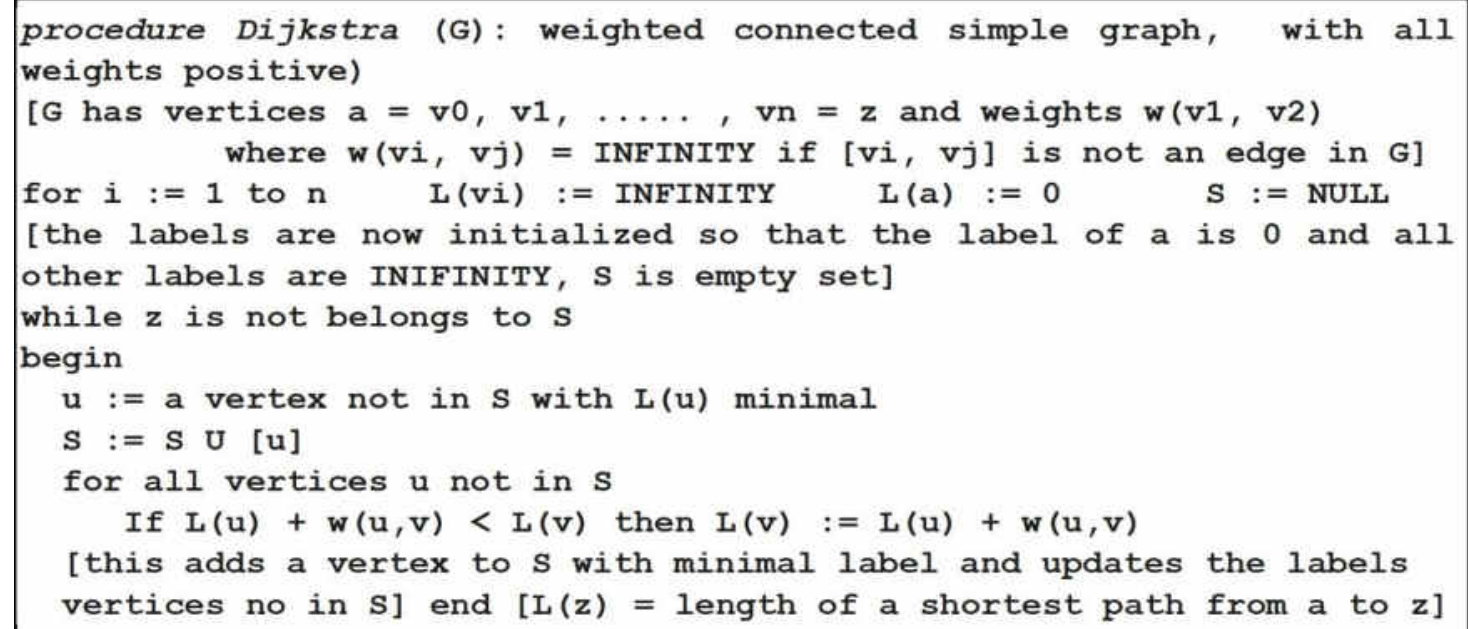

Fig. 2. Dijkstra procedure structure [12]

\section{2. All-or-nothing assignment algorithm}

Input: Given transit (O/D) trips matrix and shortest path between every main transit node pair.

Function: All - or Nothing assignment algorithm has to assign transit (O/D) trips on minimum single cost path between each two pairs, resulting in a loaded network; base network.

\section{Formulation:}

minimize $\quad \Sigma_{a} C_{a} X_{a}$

s.t.

$\sum_{k} q_{k}^{i-j}=\mathrm{d}_{\mathrm{i}-\mathrm{j}}: \forall \mathrm{i}, \mathrm{j}$

$\mathrm{X}_{\mathrm{a}}=\sum_{k} \sum_{i} \sum_{j} \delta_{a, k}^{i-j} q_{k}^{i-j}: \forall \mathrm{a}$

$q_{k}^{i-j} \geq 0: \forall \mathrm{k}, \mathrm{i}, \mathrm{j}$

$X_{\mathrm{a}} \geq 0: \mathrm{a} \in \mathrm{A}$

$C_{a}=$ the fixed cost on link (a) (time or distance)

$X_{a}=$ the total flow on link (a)

$q_{\mathrm{k}}^{\mathrm{i}-\mathrm{j}}=$ flow on path $\mathrm{k}$ connecting node (i) ans (j)

$\mathrm{d}_{\mathrm{i}-\mathrm{j}}=$ total emand between (i) and (j)

$\mathrm{A}=$ the set of network links

$\delta_{a, k}^{i-j}=$ dummy variable, 1 if flow $q_{k}^{i-j}$ passes through link (a), 0 otherwise

Journal of Engineering Sciences, Assiut University, Faculty of Engineering, Vol. 41, No. 4, July, 2013,E-mail address: jes@aun.edu.eg 
Owais M., et al., Optimal circular bus routes planning for transit network design problem in urban areas, pp. 1447 - 1466

\section{3.Optimization of network flow trips}

Input: loaded base - network; (flow trips on links considered as their upper bound at optimization process)

Function: maximizing flow on links with balance at nodes and getting high loaded directed links combination of network using linear programming algorithm (LP)

\section{LP Formulation:}

maximize $\sum_{i} \sum_{j} X_{\mathrm{i}-\mathrm{j}}$ (objective fun

s.t.

$\sum_{\mathrm{i}} X_{\mathrm{i}-\mathrm{j}}$ (in) $-\sum_{\mathrm{k} k} X_{\mathrm{j}-\mathrm{k}}$ (out) $=0 \quad \forall j$

$-b_{i-j} \leq X_{i-j} \leq b_{i-j}$

Equation (14) represents node conservation equation, since flow on links $X_{i-j}$ consists of two main types of trips:

1- Trips won't stop at node (j).

2- Trips will terminate at node $(\mathrm{j})$.

The conservation equation (14) would be written as follows:

$\sum_{i} \sum_{z} q_{\mathrm{i}-\mathrm{j}}^{\mathrm{s}}+\sum_{z} d_{\mathrm{s}-\mathrm{j}}=\sum_{k} \sum_{z} q_{\mathrm{j}-\mathrm{k}}^{\mathrm{s}}$

but;

$\sum_{k} \sum_{s} q_{\mathrm{j}-\mathrm{k}}^{\mathrm{s}}=\sum_{i \mathrm{i}} \sum_{s} q_{\mathrm{i}-\mathrm{j}}^{\mathrm{s}}+\sum_{g} d_{\mathrm{j}-\mathrm{s}}$

so it should be

$\sum_{s} d_{s-\mathrm{j}}=\sum_{s} d_{\mathrm{j}-\mathrm{s}}$

$\mathrm{X}_{\mathrm{i}-\mathrm{j}}=$ total flow on directed $\operatorname{arc}\left(\mathrm{a}_{\mathrm{i}-\mathrm{j}}\right)$

$b_{i-j}=$ flow value obtained from assignment step

$\mathrm{q}_{\mathrm{i}-\mathrm{j}}^{\mathrm{s}}=$ flow on arc (i-j) with destination node $(\mathrm{s})$, provided $\mathrm{j} \neq \mathrm{s}, \quad \mathrm{i} \neq \mathrm{s}$

$\mathrm{q}_{\mathrm{j}-\mathrm{k}}^{\mathrm{s}}=$ flow on $\operatorname{arc}(\mathrm{j}-\mathrm{k})$ with destination node $(\mathrm{s})$, provided $\mathrm{j} \neq \mathrm{s}$

$\mathrm{d}_{\mathrm{s}-\mathrm{j}}=$ demand flow trips terminated at node $(\mathrm{j})$ (originated from node $(\mathrm{s})$ )

$\mathrm{d}_{\mathrm{j}-\mathrm{s}}=$ demand flow trips generated at node $(\mathrm{j})$ (destinated to node $(\mathrm{s})$ )

Considering maximizing transit flows on network links (eq.13) and achieving balance at nodes (eq.14); giving limited capacities on links to carry flows (eq.15); it is an optimization problem of the network flows. Finding maximum flows on links involves looking at all of the possible routes of flows between the two end nodes. The links represent channels of flow with limited capacities; (bounds). To find the maximum flow on links, LP assigns flow to each link in the network within a margin of upper and lower bounds on the links; so that the simultaneous flow between the two end points is as large as possible.

To reach equilibrium (eq.14), LP works on simultaneous process maximizing flows and adjusting values of demand flow trips generated or terminated at every node (j) and this will guarantee number of homogenous trips on links. This number of trips guarantees that at every node (j) the number of terminated (alighted) trips is equal to the number of

Journal of Engineering Sciences, Assiut University, Faculty of Engineering, Vol. 41, No. 4, July, 2013,E-mail address: jes@aun.edu.eg 
Owais M., et al., Optimal circular bus routes planning for transit network design problem in urban areas, pp. 1447 - 1466

generated (boarded) trips. Thus, every bus (same seat capacity) on the transit network would be running with the same load factor along its route which will give high efficiency to bus system (least cost).

Directed graph is presented at equation (15), that there are upper and lower bounds of the flows on the links, (i.e. the variables in the model). This research modeling system will allow a negative lower bound on the link flow. This means; if $\mathrm{Xi}-\mathrm{j}$ takes a negative value, it is an opposite flow direction on that link (i.e. the direction of flow is from (j) to (i)).

Resulting output of this step would be a loaded equilibrated base - network with maximum flow on links; this would be applied as input for constructing bus routes.

\section{4. Construction of bus routes}

Input: Loaded equilibrated base - network with maximum flow on links.

Function: Integer Programming (IP) is used to construct a set of circular closed bus routes maximizes demand coverage on each bus route confirming to maximum allowable bus route time constraint.

\section{IP Formulation:}

$$
\begin{array}{lll}
\operatorname{maximize} & \sum_{i \mathrm{i}} \sum_{j} \delta_{\mathrm{i}-\mathrm{j}} \mathbf{X}_{\mathrm{i}-\mathrm{j}} \\
\text { s.t. } & & \\
& \sum_{i} \sum_{j} \delta_{\mathrm{i}-\mathrm{j}} \mathrm{t}_{\mathrm{i}-\mathrm{j}} \leq \mathrm{T}_{\max } & \\
& \sum_{i} \delta_{\mathrm{i}-\mathrm{j}}=\sum_{k} \delta_{\mathrm{j}-\mathrm{k}} & \forall \mathrm{j} \\
& \sum_{i \mathrm{i}} \delta_{\mathrm{i}-\mathrm{j}}+\sum_{k} \delta_{\mathrm{j}-\mathrm{k}} \leq 2 & \forall \mathrm{j} \\
& \text { for } \mathrm{i}, \mathrm{j}, \mathrm{k} \in \mathrm{N}
\end{array}
$$

$\mathrm{X}_{\mathrm{i}-\mathrm{j}}=$ flow on $\operatorname{arc}\left(\mathrm{a}_{\mathrm{i}-\mathrm{j}}\right)$, obtained from optimization (section 4.3)

$\delta_{\mathrm{i}-\mathrm{j}}=$ dummy variable equal to 1 if directed arc (i-j) belongs to route (r) is included, 0 otherwise

$\mathrm{t}_{\mathrm{i}-\mathrm{j}}=$ arc travel time

$\mathrm{T}_{\max }=$ maximum bus round trip travel time

Equation constraint (eq.20) asserts that bus round trip travel time won't exceed its maximum time, (eq.21) provides a connected bus route and (eq.22) assures that every node will by visited once at most. If designer prefers certain number of nodes $(\mathrm{m})$ should be visited, he could add this constraint; ${ }^{\sum_{i} \delta} \mathrm{i}-\mathrm{m}+{ }^{\sum_{k} \delta} \mathrm{m}-\mathrm{k}=2^{\forall} \mathrm{m}$; but this constraint may make the solution infeasible (depending on m nodes selection) due to directed graph condition.

Integer programming algorithm is a search tool for constructing a circular closed bus route from directed graph touching desired high demand nodes and links and performs with route time constraint. Optimality of route is measured in terms of highest loaded links (demand coverage) forming the route [13].

Journal of Engineering Sciences, Assiut University, Faculty of Engineering, Vol. 41, No. 4, July, 2013,E-mail address: jes@aun.edu.eg 
Owais M., et al., Optimal circular bus routes planning for transit network design problem in urban areas, pp. 1447 - 1466

\section{The structure of deterministic route generation algorithm (DRGA)}

The structure of DRGA is graphically depicted in figure (3). Bus route construction design algorithm is presented in the following steps; these are:

Step1. Construct coded route network.

Step2. Indentify travel time on links.

Step3. Sort transit $\mathrm{O} / \mathrm{D}$ demand matrix in descending order according to nodes' total demand trips.

Step4. Identify the main transit nodes $(\mathrm{N})$ with the highest total demand in sorted matrix (select the nodes from the sorted matrix till their total demand satisfy minimum number of trips required to be covered directly ( $\geq$ Domin)).

Step5. Create shortest path between every main transit node pair (see section 4.1), reaching base - network.

Step6. Assign main nodes transit trips using All - or - Nothing algorithm (see section 4.2), reaching loaded base - network.

Step7. Assign half loaded links values and assume arbitrary directed graph arrows (N.B the algorithm adjusts the direction later on reaching maximum balanced network flows).

Step8. Optimize the loaded base - network (see section 4.3), reaching equilibrated directed loaded base - network.

Step9. Identify the first circular closed bus route (see section 4.4), covering the highest loaded links, set $\mathrm{K}=1$.

Step10. Construct Kth bus closed route with defined minimum loaded link trips on its path (step. 9) as loaded route with lower bound demand needs to be covered by bus service.

Step11. Subtract defined route trips (step. 10) along its path from equilibrated assigned base - network links and then remove links with (0) trips from the network.

Step12. Get updated loaded base - network.

Step13. Delete all (O/D) pairs cells from (O/D) matrix that covered by the route path to calculate Do

Step14. Check if all assigned demand trips (-0- transfer) on the network are satisfied by Kth routes; otherwise set $\mathrm{K}=\mathrm{K}+1$, then go to step. 9 .

Step15. Compute the total demand satisfied by the set of Kth routes (using -0- or -1transfer), if that demand $\geq$ Dtotmin (the minimum total demand needed to be satisfied) terminate DRGA process and output the set $\mathrm{K}$ routes; otherwise, set $\mathrm{N}=\mathrm{N}+1$, and then go to step4.

Journal of Engineering Sciences, Assiut University, Faculty of Engineering, Vol. 41, No. 4, July, 2013,E-mail address: jes@aun.edu.eg 
Owais M., et al., Optimal circular bus routes planning for transit network design problem in urban areas, pp. 1447 - 1466

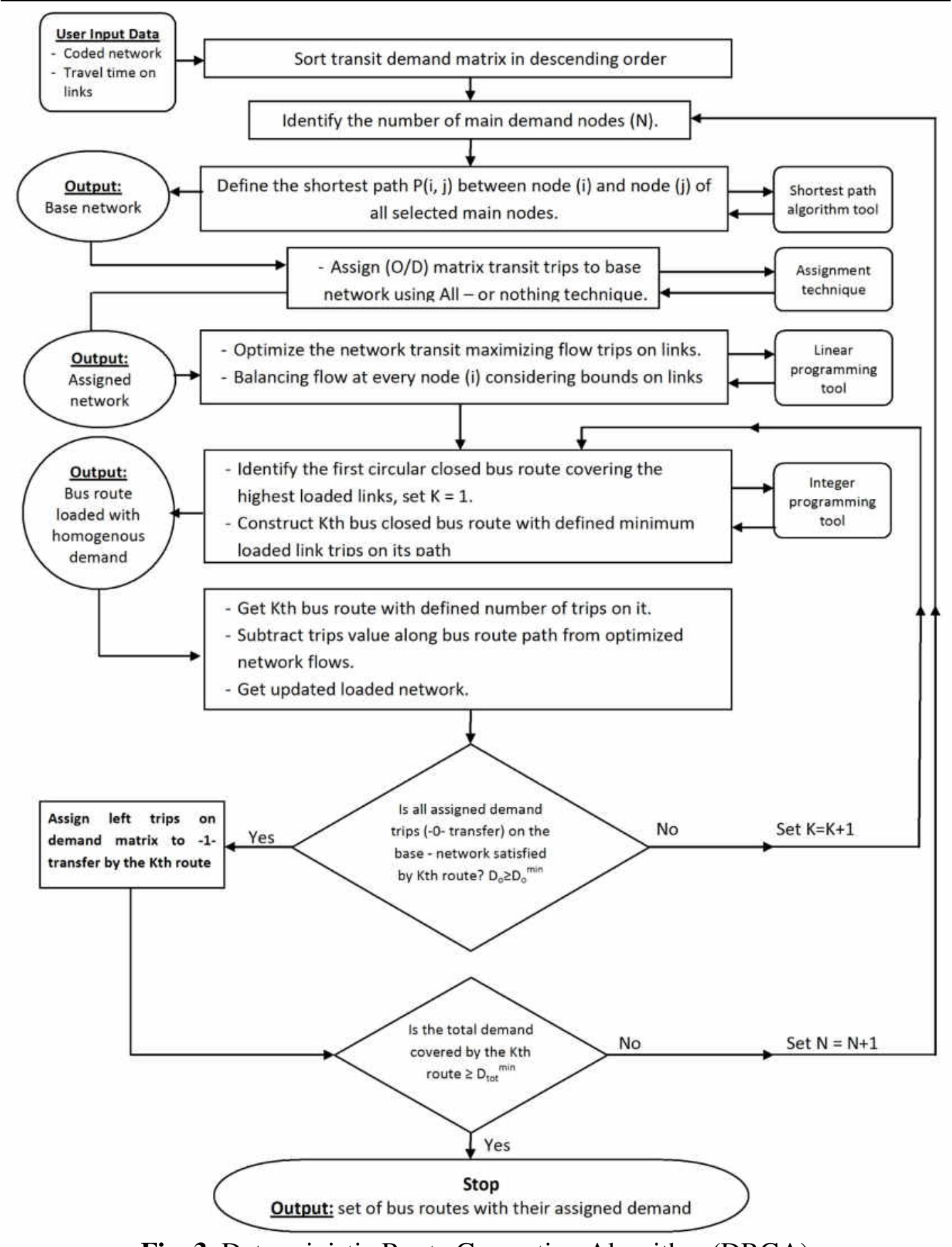

Fig. 3. Deterministic Route Generation Algorithm (DRGA)

Journal of Engineering Sciences, Assiut University, Faculty of Engineering, Vol. 41, No. 4, July, 2013, E-mail address: jes@aun.edu.eg 
Owais M., et al., Optimal circular bus routes planning for transit network design problem in urban areas, pp. 1447 - 1466

\section{Illustrative numerical example solution using DRGA (mandl's transit network)}

In order to demonstrate the effectiveness of suggested solution methodology algorithm (DRGA), which is proposed in this paper, a popular benchmark network is solved. Mandl's Swiss transit network and transit demand matrix reproduced from Mandl 1979 [14] has been utilized by Baaj and Mahmassani [15], Shih and Mahmassani [16], Zhao, F. [17], Bagloee and Ceder [18] and other researchers as benchmark problem to compare their results with Mandl's solution results. Mandl's network consists of 15 nodes connected by 21 links, see figure (4).

N.B: nodes $(0,8)$ were excluded from the analysis since; DRGA algorithm doesn't work with nodes connected by only one link (DRGA searches only for circular closed bus routes).

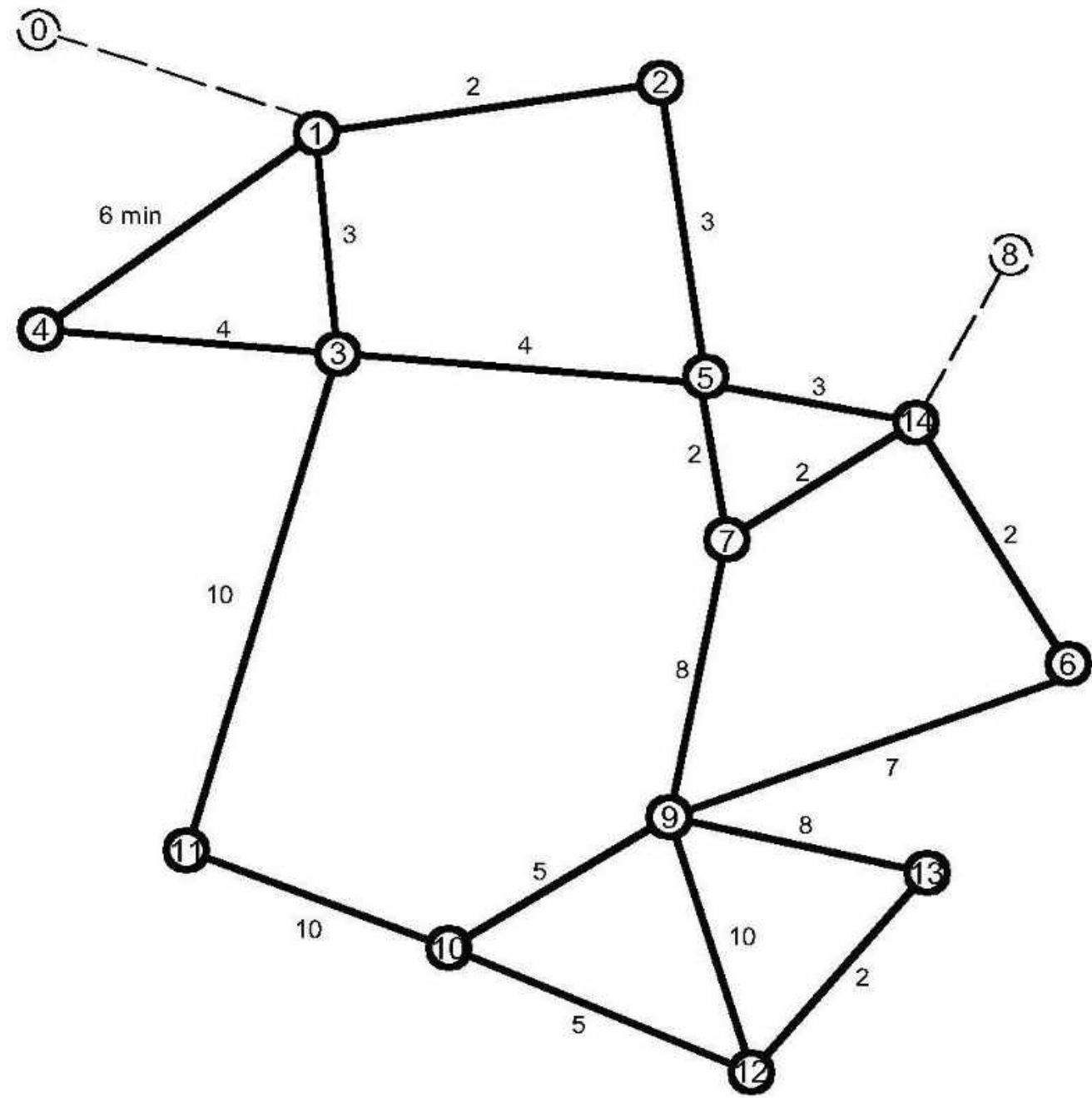

Fig. 4. Coded network with travel time on links in minutes [14]

Journal of Engineering Sciences, Assiut University, Faculty of Engineering, Vol. 41, No. 4, July, 2013,E-mail address: jes@aun.edu.eg 
Owais M., et al., Optimal circular bus routes planning for transit network design problem in urban areas, pp. 1447 - 1466

Transit (O/D) matrix is given in table (3). DRGA analysis included all nodes $(\mathrm{N}=13)$ to examine methodology strength in solving the whole network at once. Solution methodology implements steps that are presented in section (5) of this paper considering these data:

- Bus route Constraints:

- $\mathrm{D}_{\mathrm{o}}^{\min } \geq 75 \%$

- $\mathrm{d}(\mathrm{R})_{\max } \leq 1.25$

- Max bus route length $\left(\mathrm{T}_{\text {max }}^{\mathrm{r}} \leq 60 \mathrm{~min}\right)$.

Table 3

Transit O/D trips matrix [14]

\begin{tabular}{ccccccccccccccccc}
\hline$O / D$ & 0 & 1 & 2 & 3 & 4 & 5 & 6 & 7 & 8 & 9 & 10 & 11 & 12 & 13 & 14 \\
\hline 0 & 0 & 400 & 200 & 60 & 80 & 150 & 75 & 75 & 30 & 160 & 30 & 25 & 35 & 0 & 0 \\
\hline 1 & 400 & 0 & 50 & 120 & 20 & 180 & 90 & 90 & 15 & 130 & 20 & 10 & 10 & 5 & 0 \\
2 & 200 & 50 & 0 & 40 & 60 & 180 & 90 & 90 & 15 & 45 & 20 & 10 & 10 & 5 & 0 \\
3 & 60 & 120 & 40 & 0 & 50 & 100 & 50 & 50 & 15 & 240 & 40 & 25 & 10 & 5 & 0 \\
4 & 80 & 20 & 60 & 50 & 0 & 50 & 25 & 25 & 10 & 120 & 20 & 15 & 5 & 0 & 0 \\
5 & 150 & 180 & 180 & 100 & 50 & 0 & 100 & 100 & 30 & 880 & 60 & 15 & 15 & 10 & 0 \\
6 & 75 & 90 & 90 & 50 & 25 & 100 & 0 & 50 & 15 & 440 & 35 & 10 & 10 & 5 & 0 \\
7 & 75 & 90 & 90 & 50 & 25 & 100 & 50 & 0 & 15 & 440 & 35 & 10 & 10 & 5 & 0 \\
8 & 30 & 15 & 15 & 15 & 10 & 30 & 15 & 15 & 0 & 140 & 20 & 5 & 0 & 0 & 0 \\
\hline 9 & 160 & 130 & 45 & 240 & 120 & 880 & 440 & 440 & 140 & 0 & 600 & 250 & 500 & 200 & 0 \\
10 & 30 & 20 & 20 & 40 & 20 & 60 & 35 & 35 & 20 & 600 & 0 & 75 & 95 & 15 & 0 \\
11 & 25 & 10 & 10 & 25 & 15 & 15 & 10 & 10 & 5 & 250 & 75 & 0 & 70 & 0 & 0 \\
12 & 35 & 10 & 10 & 10 & 5 & 15 & 10 & 10 & 0 & 500 & 95 & 70 & 0 & 45 & 0 \\
13 & 0 & 5 & 5 & 5 & 0 & 10 & 5 & 5 & 0 & 200 & 15 & 0 & 45 & 0 & 0 \\
14 & 0 & 0 & 0 & 0 & 0 & 0 & 0 & 0 & 0 & 0 & 0 & 0 & 0 & 0 & 0 \\
\hline
\end{tabular}

N.B: Hatched cells denote excluded nodes from the analysis

\section{1. Results and discussions}

Solution methodology has been resulted in four circular closed bus routes connecting transit nodes with direct demand coverage (Do) $=84.41 \%$ and indirect demand coverage $($ Do1 $=15.43 \%$, Do2 $=0.16$ i.e. total demand coverage $=100 \%)$. All routes lengths comply with maximum route time constraint $\leq 60 \mathrm{~min}$. Although DRGA provides set of high demand coverage routes, it keeps a good value of routes directness $d(R)=1.05$. Results are summarized in table (4) and routes configuration is depicted in figure (5).

Journal of Engineering Sciences, Assiut University, Faculty of Engineering, Vol. 41, No. 4, July, 2013,E-mail address: jes@aun.edu.eg 
Owais M., et al., Optimal circular bus routes planning for transit network design problem in urban areas, pp. $1447-1466$

\section{Table 4.}

DRGA results

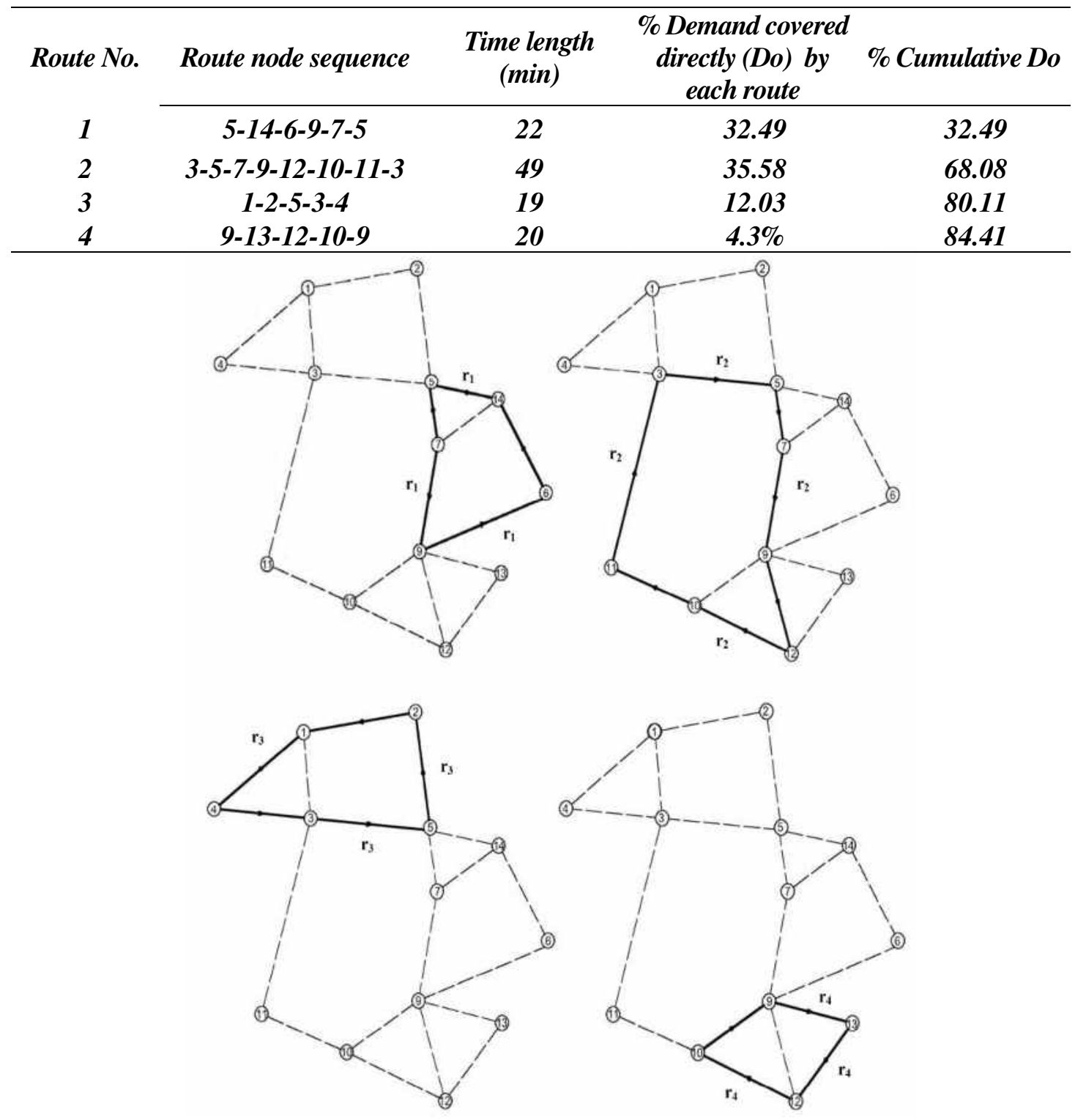

Fig. 5. Deterministic Route Generation Algorithm (DRGA) routes set configuration N.B: There is reversible route direction for each of the four constructed route

Table (5) presents a comparison between DRGA analysis results and highlighted previous works which tackled Mandl's network in their solution as benchmark problem. It

Journal of Engineering Sciences, Assiut University, Faculty of Engineering, Vol. 41, No. 4, July, 2013,E-mail address: jes@aun.edu.eg 
1463

Owais M., et al., Optimal circular bus routes planning for transit network design problem in urban areas, pp. $1447-1466$

is worth noting that DRGA constructed routes are circular ones, but other methods in the comparison construct open bus routes service (bus moves forward and backward on the same line).

Table 5.

Comparison of Approaches for Mandl's Benchmark Network problem with DRGA

\begin{tabular}{|c|c|c|c|c|c|c|c|c|c|c|}
\hline $\begin{array}{l}\text { Problem } \\
\text { source }\end{array}$ & \multicolumn{2}{|c|}{ Mandl [14] } & \multicolumn{2}{|c|}{$\begin{array}{c}\text { Baaj and } \\
\text { Mahmassani [15] }\end{array}$} & \multicolumn{2}{|c|}{$\begin{array}{c}\text { Shih and } \\
\text { Mahmassani } \\
\text { [16] }\end{array}$} & \multicolumn{2}{|c|}{ Fang Zaho [17] } & \multicolumn{2}{|c|}{$\begin{array}{c}\text { Bagloee } \\
\text { \&Ceder } \\
{[18]}\end{array}$} \\
\hline Year & \multicolumn{2}{|c|}{1980} & \multicolumn{2}{|c|}{1991} & \multicolumn{2}{|c|}{1994} & \multicolumn{2}{|c|}{2003} & \multicolumn{2}{|c|}{2011} \\
\hline Search method & Mandl ${ }^{l}$ & $D R G A$ & $B \& M^{2}$ & $D R G A$ & $S \& M^{3}$ & $D R G A$ & $\boldsymbol{F H C} C^{4}$ & $D R G A$ & \begin{tabular}{|l|}
$G I \&$ \\
$A S^{5}$ \\
\end{tabular} & $D R G A$ \\
\hline $\begin{array}{c}\text { Number of } \\
\text { routes }\end{array}$ & 4 & 4 & 7 & 4 & 8 & 4 & 6 & 4 & 12 & 4 \\
\hline $\begin{array}{c}\text {-0- transfer trips } \\
\left(D_{o}\right)\end{array}$ & 69.94 & 84.41 & 80.99 & 84.41 & 87.73 & 84.41 & 89.92 & 84.41 & 83.66 & 84.41 \\
\hline $\begin{array}{l}\text { One transfer } \\
\text { trips\% }\left(D_{o l}\right)\end{array}$ & 29.93 & 15.43 & 19.01 & 15.43 & 12.27 & 15.43 & 10.08 & 15.43 & 15.21 & 15.43 \\
\hline $\begin{array}{c}\text { Two transfer } \\
\text { trips } \%\left(D_{02}\right)\end{array}$ & 0.13 & 0.16 & 0 & 0.16 & 0 & 0.16 & 0 & 0.16 & 0.95 & 0.16 \\
\hline $\begin{array}{l}\text { Total Demand } \\
\text { satisfied }\left(D_{\text {tot }}\right)\end{array}$ & 100 & 100 & 100 & 100 & 100 & 100 & 100 & 100 & 99.82 & 100 \\
\hline $\begin{array}{c}\text { Network } \\
\text { directness } d(R)\end{array}$ & 1.05 & 1.05 & 1.16 & 1.05 & 1.03 & 1.05 & 1.06 & 1.05 & $R N R^{6}$ & 1.05 \\
\hline $\begin{array}{c}\text { Transfer } \\
\text { directness }^{7}\end{array}$ & 1.3 & 1.06 & 1.19 & 1.06 & 1.12 & 1.06 & 1.10 & 1.06 & $R N R$ & 1.06 \\
\hline $\begin{array}{c}\text { Total route time } \\
\text { length }(\mathrm{min})\end{array}$ & 82 & 110 & 106 & 110 & 151 & 110 & 127 & 110 & 261 & 110 \\
\hline $\begin{array}{c}\text { Total trips / } \\
\text { route length } \\
\text { (pass./min) }\end{array}$ & 190 & 113 & 147 & 113 & 103 & 113 & 126 & 113 & 60 & 113 \\
\hline${ }^{4}$ Fast H & 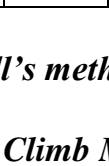 & & & 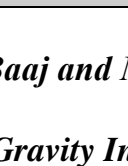 & 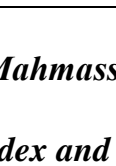 & $i$ 's & & ${ }^{6} \operatorname{Resu}$ & $\begin{array}{l}\text { etho } \\
\text { not } \mathrm{I}\end{array}$ & 's \\
\hline
\end{tabular}

The results from DRGA are given in table (5) along with those from previous work. The first row indicates the source of the solutions to the benchmark problem. The second row gives the previous work year. The third row identifies the solutions methods to the problem. The comparison is made based on parameters that reflect the quality of transit route network design, such as number of routes, the percentage of demand transferred directly (Do) and indirectly (Do1, Do2), network directness and etc. The comparison

Journal of Engineering Sciences, Assiut University, Faculty of Engineering, Vol. 41, No. 4, July, 2013,E-mail address: jes@aun.edu.eg 
Owais M., et al., Optimal circular bus routes planning for transit network design problem in urban areas, pp. 1447 - 1466

depends on objective function values and design variables that characterize transit route network design.

We consider the number of route generated, in regard with other parameters of comparison, the most important criteria in judging the efficiency of any of these search methods. Less number of routes demonstrates the methodology strength in assembling candidate links in one continuous bus route and entails - accordingly - less number of common lines, which reduces the computational effort of scheduling part.

Suggested DRGA results - in comparison with previous work - have been found in general are much better than other ones in number of constructed routes regarding other parameter of comparison. DRGA constructed four routes with total route length $=110 \mathrm{~min}$ to achieve demand coverage $(\mathrm{Do}=84.41 \%$, Do1 $=15.43 \%$, Do2 $=0.16)$, however S\&M [16] -for example- constructed eight routes with route length $=151 \mathrm{~min}$ to achieve demand coverage $($ Do $=87.73 \%$, Do1 $=12.27)$. Bagloee and Ceder [18] (recent research) implemented intense mathematical programming representation equipped with two search heuristic algorithms (Genetic Algorithm and Ant System) to produce twelve bus routes covering $83.66 \%$ directly with total route length $261 \mathrm{~min}$.

DRGA increases the transit attractiveness through keeping the best value of network directness considering total network directness along with transfer directness. It has the minimum value of transfer directness $=1.06$, so it would encourage even indirect origin destination trips to take the transit service.

DRGA solution reliability is higher than other methods (Heuristics and Meta heuristics); since it uses exact methods in solving its Mathematical Programming representation which ensures the same solution with the rerun of the algorithm. CPU running time is incomparable between DRGA which depends on Mathematical basis on its solution and other stochastic methods. DRGA is fast and efficient method for bus route design.

\section{Conclusions}

Suggested solution methodology has resulted in a Deterministic Route Generation Algorithm (DRGA). The key features of the DRGA solution methodology are:

1- The output of this solution methodology is a set of efficient circular closed bus routes, routes lengths and their lower bound assigned demand trips which would be used as input for further research; tackling transit route service operation management,(i.e. seeking the optimal transit vehicle scheduling, fleet size and performance for each bus route operation service).

2- The solution results have a high percentage of route directness and demand coverage and it is applicable to small, medium and large size networks.

3- It would be applicable to symmetric and unsymmetrical (O/D) matrices.

4- For each generated closed bus route there is an opposite direction route and has the same defined loaded trips for symmetric (O/D) matrix.

5- It is applicable to two-way in addition to one-way street systems.

Journal of Engineering Sciences, Assiut University, Faculty of Engineering, Vol. 41, No. 4, July, 2013,E-mail address: jes@aun.edu.eg 
Owais M., et al., Optimal circular bus routes planning for transit network design problem in urban areas, pp. 1447 - 1466

6- Adopted solution methodology is flexible; since planner can classify generated bus routes according to demand coverage, which enables operator to execute selected routes according to available existing resources.

7- It confirms to several network routes configurations.

8- No need for designer to implement his judgment and knowledge in the solution process.

9- Solution methodology implemented standard linear mathematical programming which enables one to reach solution in a fast way (less CPU time).

10- It would overcome the pervious researches on transit network draw - backs and short comings reviewed so - far.

\section{Acknowledgment}

The author(s) would like to express their gratitude to Prof. Owais, M.A Prof. of transportation planning \& Traffic Eng., Civil Eng. Dept. Assuit Univ. (A.R.E), for his valuable advices and recommendations which contributed to this research work.

\section{References}

[1] Mauttonw, A. and Urquhart, M. (2009), “A Route Set Construction Algorithm for the Transit Network Design Problem” Computers and Operations Research Volume 36 Issue 8 pp. 24402449 Elsevier Science Ltd. Oxford, UK, UK.

[2] Chakroborty, P. (2003), "Genetic Algorithms for Optimal Urban Transit Network Design" Computer - Aided Civil and Infrastructure Eng. Blackwell Publishing, Malden MA 02148, USA.

[3] Ceder, A. and Wilson, N. (1986), "Bus Network Design" Transportation Research Board Part B 20 (4), pp. 331 - 344.

[4] Baaj, M. H. and Mahmassani, H. (1995), "Hybrid Route Generation Heuristic Algorithm for the Design of Transit Networks" Transportation Research Part C: Emerging Technologies, Volume 3, Issue 1, pp. 31-50.

[5] Reeves, C. (1993), "Modern Heuristic Techniques for Combinatorial Problems" John Wiley \& Sons, Inc. New York, NY, USA.

[6] Cipriani, E., Gori, S., and Petrelli, M. (2012), "Transit Network Design: A Procedure and an Application to a Large Urban Area" Transportation Research Part C: Emerging Technologies, 20 (1), 3-14.

[7] Pattnaik, S. B., Mohan, S. and Tom,V. M., (1998) "Urban Bus Transit Route Network Design Using Genetic Algorithm” Journal of Transportation Engineering - ASCE, Vol. 124, No. 4, pp. 368-375.

[8] Gao, Z, Sun, H. and Shan, L. (2004), “A Continuous Equilibrium Network Design Model and Algorithm for Transit Systems" Transportation Research Part B: Methodological, Volume 38, Issue 3, p. 235-250.

[9] Guan, J, Yang, H, and Wirasinghe, S, (2006), "Simultaneous Optimization of Transit Line Configuration and Passenger Line Assignment" Transportation Research Part B: Methodological, Volume 40, Issue 10, pp 885-902.

Journal of Engineering Sciences, Assiut University, Faculty of Engineering, Vol. 41, No. 4, July, 2013,E-mail address: jes@aun.edu.eg 
Owais M., et al., Optimal circular bus routes planning for transit network design problem in urban areas, pp. 1447 - 1466

[10] Yu B, Yang ZZ, Jin PH, Wu SH, Yao BZ, (2012), "Transit Route Network DesignMaximizing Direct And Transfer Demand Density" Transportation Research Part C: Emerging Technologies Volume 22, p. 58-75.

[11] Newell, G. (1979), "Evaluation and Optimization of Urban Public Transport Networks" 3rd European Congress on Operation Research, Amsterdam, Netherlands.

[12] Chinneck, J. W. (2010) "Practical Optimization: A Gentle Introduction" [online] Available: http://www.sce.carleton.ca/faculty/chinneck/po.html.

[13] Sheffi, Y. (1985) "Urban Transportation Networks Equilibrium Analysis with Mathematical Programming Methods, Inc. Englewood Cliffs, New Jersey.

[14]Mandl, C.E. (1980), "Evaluation and Optimization of Urban Public Transportation Networks", European Journal of Operation Research, Vol. 5, pp. 396-404.

[15] Baaj, M. H. and Mahmassani, H. (1991), "An AI-Based Approach for Transit Route System Planning and Design", Journal of Advance Transportation Vol. 25, No. 2, pp. 187-210.

[16] Shih, Mao-Chang and Mahmassani, H.(1994), " A Design Methodology for Bus Transit Networks with Coordinated Operation", SWUTC/94/60016-1, Center for Transportation, Bureau of Engineering Research, the University of Texas at Austin, Austin, Texas.

[17] Zhao, F. and Gan, A. (2003) "Optimization of Transit Network to Minimize Transfers" Final Report, Research Office Florida Department of Transportation 605 Suwannee Street, MS 30 Tallahassee FL 32399-0450.

[18] Bagloee, S. and Ceder, A. (2011), "Transit-network design methodology for actual-size road networks" Transportation Research Part B: Methodological, Volume 45, Issue 10, pp 1787-1804.

\section{تخطيط أفضل خطوط أتوبيسات دائرية من أجل مشكلة تصميم شبكات النقل العام

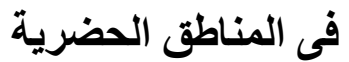

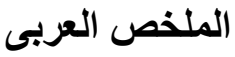

يستعرض هذا البحـث منهجيـة حل للتوصـل لأفضـل تخطيط لثبكة خطوط أتوبيسـات دائريسة في المنـاطق

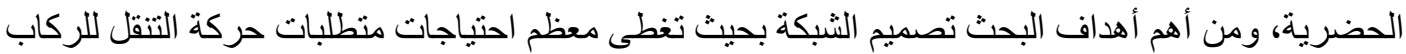

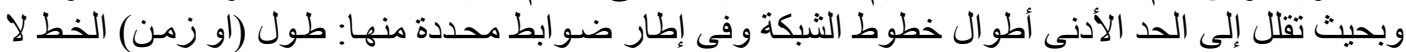

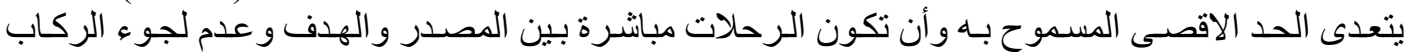

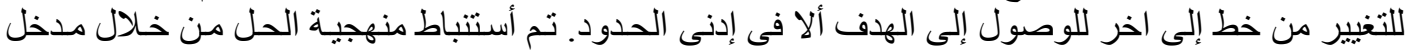

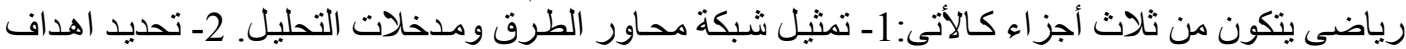

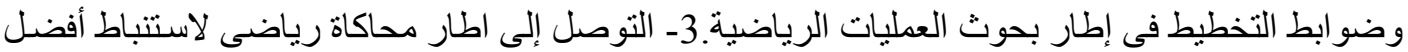

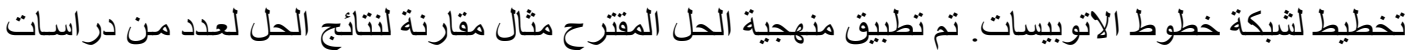

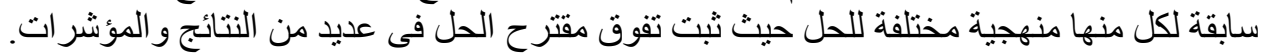

Journal of Engineering Sciences, Assiut University, Faculty of Engineering, Vol. 41, No. 4, July, 2013,E-mail address: jes@aun.edu.eg 